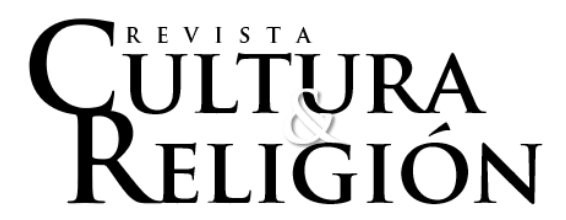

Vol. XIV, N’ 2 (2020) pp. 56-78.

Recibido: 17 de marz0, 2020

Aceptado: 14 de julio, 2020

\title{
EL ESTABLECIMIENTO Y EXPANSIÓN DE LA MISIÓN EVANGÉLICA THE CHRISTIAN AND MISSIONARY ALLIANCE EN EL SUR DE CHILE (1897-1905)*
}

\author{
The establishment and expansion of The Christian and Missionary Alliance \\ evangelical mission in south Chile. 1897-1905.
}

\author{
Darío Escobar Sepúlveda** \\ Universidad de Los Lagos \\ dario.escobar@ulagos.cl
}

\author{
Paula Gabriela Núñez ${ }^{* * *}$ \\ Universidad de Los Lagos \\ paula.nuñez@ulagos.cl
}

\begin{abstract}
Resumen
Este artículo explora el establecimiento misional de la misión evangélica The Christian and Missionary Alliance, de origen estadounidense, en el sur de Chile. Indaga en la construcción de un territorio de fe, a la luz de la integración socioespacial resuelta en torno a este culto. La hipótesis que guía este trabajo apunta a que para investigar el establecimiento de una misión religiosa se debe problematizar tanto en el movimiento como en las marcas territoriales de esta, en diálogo con la propuesta teológica que busca expandir. Se observa aquí que a partir del establecimiento efectivo de la misión evangélica, se modificaron la modalidad pastoral y sus marcas.
\end{abstract}

Palabras clave: The Christian and Missionary Alliance, sur chileno, territorio de fe, movimiento pastoral, marcas territoriales.

\footnotetext{
* El presente artículo es resultado del proyecto PIP 11220150100838, "Biopolítica de la territorialización norpatagónica en el siglo XX", financiado por el Consejo Nacional de Investigaciones Científicas y Técnicas (CONICET-Argentina). Agradecemos la cuidadosa y enriquecedora lectura de los/as dos revisores/as anónimos/as, cuyos aportes mejoraron notablemente la propuesta original.

${ }^{* *}$ Magíster en Ciencias Humanas, mención Historia, Departamento de Ciencias Sociales, Universidad de Los Lagos. ORCID ID: https://orcid.org/0000-0002-4477-1849

${ }^{* * *}$ Departamento de Ciencias Sociales, Universidad de Los Lagos-Instituto de Investigaciones en Diversidad Cultural y Procesos de Cambio (IIDYPCA), Universidad Nacional de Río Negro (Argentina)-CONICET. ORCID ID: https://orcid.org/0000-0002-2008-2643
} 


\begin{abstract}
This article explores the missionary establishment of the Evangelical Mission The Christian and Missionary Alliance, of North American origin, in southern Chile. It will investigates the construction of a territory of faith, in the light of the socio-spatial integration resolved around this cult. The hypothesis that guides this work is that to investigate the establishment, both movement and territorial brands must be problematized in dialogue with the theological proposal that was trying to expand. We show that after the effective establishment of the Evangelical Mission, the pastoral modality and its marks were modified.
\end{abstract}

Keywords: The Christian and Missionary Alliance, southern Chilean, territory of faith, pastoral movement, territorials marks.

\title{
Introducción
}

La historiografía chilena reconoce extensos antecedentes en investigaciones eclesiales. Camus (2001) ordenó estos antecedentes en torno a cinco temáticas: la independencia, la relación Iglesia-Estado, la actividad misionera, las reuniones sinodales y el análisis crítico de fuentes pastorales. Este autor pertenece a una tradición que da por sentado que los estudios eclesiales corresponden a los de la Iglesia católica, y por ello ubicó temporalmente la práctica de esta iglesia en relación con los órdenes estatales, tanto coloniales como nacionales, evidenciando apropiaciones territoriales como parte de esta articulación.

El presente artículo propone una complejización de geografías, temporalidades y procesos desde un caso que pregunta por una iglesia fuera de las revisiones mayoritarias. Para ello dialoga con la geografía de la religión indagando en cómo se fue construyendo el territorio de fe (Carballo y Flores, 2019; Govea, 2016, Rodrigues, 2016) en la práctica de la misión de origen estadounidense The Christian and Missionary Alliance (en adelante The Alliance), en el sur de Chile a fines del siglo XIX. Se propone en este texto investigar la configuración del territorio desde las trayectorias móviles de la práctica pastoral y el discurso teológico, y desde el establecimiento de marcas materiales, observando distintos niveles de disputa.

Como indica Govea (2016), la religiosidad es una expresión cultural con la que algunos grupos signan el espacio geográfico mediante una serie de prácticas rituales históricas. Esto institucionaliza simbólicamente el espacio, cobrando sentido tanto para quienes lo habitan como para quienes no lo hacen. El caso de The Alliance permite observar un proceso poco conocido, en el que la marginalidad y la escasa cantidad de fieles al momento del establecimiento resultaron en un reconocimiento poco convencional de poblaciones usualmente distantes de cargos eclesiales, como son las nativas y las mujeres. Además, se enmarcaba un escenario de secularización nacional y de búsqueda de avances en la modernización del territorio, donde esta propuesta religiosa protestante promovió internamente la visibilización de actores subalternos, generando nuevas tensiones en el territorio.

A lo largo del artículo iremos recorriendo dinamismos de apropiación material de creencias y no solo de prácticas de sacramentos (Camus, 2001). Para ello, pondremos en tensión el par establecimiento-movimiento, pues entendemos que la práctica pastoral se 
reconoce en las acciones ligadas a las prácticas de fe, pero también en las trayectorias territoriales de la fe que se buscaba establecer. Mostraremos cómo la práctica pastoral configuró territorios de fe que disputaron sentidos espaciales, tanto en términos de las creencias como en términos políticos y económicos en la compleja construcción de nación que se dio en el sur de Chile a fines del siglo XIX (Muñoz, 2018).

Los conflictos que suscitó la llegada de esta misión han sido estudiados por Escobar (2020), quien evidenció disputas sobre la base de argumentos litúrgicos que impactaron en los sentidos espaciales urbanos a partir del establecimiento de lugares de culto (Escobar y Núñez, 2018). The Alliance llegó a Chile en 1897, cuando estaba vigente la Constitución de 1833, que establecía el catolicismo como religión oficial y prohibía la reproducción y el ejercicio público de otros cultos, inscribiendo la práctica misional que nos ocupa en el marco jurídico de lo ilegal (Escobar, 2020). Aun cuando la Constitución chilena planteaba la legalidad exclusiva de la religión católica, a la llegada de esta misión norteamericana ya se habían ampliado sus límites. La promoción estatal de una migración centroeuropea produjo el ingreso de corrientes religiosas no católicas al territorio del sur.

En la segunda mitad del siglo XIX, alemanes, austriacos y suizos trajeron consigo prácticas, devociones y discursos (Collier, 2005). Este ingreso de población extranjera modificó prácticas religiosas, lo cual devino en una contribución a la secularización del Estado chileno, ${ }^{1}$ así como a la modernización y el desarrollo regional (Muñoz, 2018). La fe, legalmente hegemonizada por la Iglesia católica, se abría al reconocimiento de otras prédicas, por la relevancia económica de los fieles que las practicaban.

En este escenario se situó el ingreso de tres misioneros independientes enviados por The Alliance desde Estados Unidos a Chile. Fue una estrategia que esperaba sumarse a la extensa incorporación de protestantes al territorio. Holland (2009) reconoció 18 establecimientos protestantes en Chile desde 1811 hasta el establecimiento de The Alliance, que en algunos casos se articularon en torno a sus iniciativas y en otros se contrapusieron.

Nuestra hipótesis sostiene que, desde el análisis del movimiento, esto es, desde las trayectorias de prédica delineadas por los misioneros, y a la luz de sus discursos pastorales, podemos reconocer las particularidades de valores que se buscaban expandir en la práctica misional y con ello caracterizar la constitución del territorio de la fe.

Buscaremos mostrar que el método inicial utilizado por los misioneros de The Alliance en el sur chileno fue el de las "misiones circulares". Una estrategia de evangelización empleada en el siglo XVI por la Compañía de Jesús (Hernández y Moreno 2010) que marcó el modo de evangelizar el sur de Chile (Gutiérrez, 2007; Moreno, 2007), la cual The Alliance modificó en los años subsiguientes, dando lugar a conflictos.

En este estudio se utilizarán como fuentes primarias los discursos, reportes y testimonios de los propios misioneros, publicados en el periódico Christian and Missionary Alliance que esta misión editaba semanalmente en Estados Unidos. A estas extensas fuentes, se agregan los libros de textos editados por la propia iglesia, que corresponden a los escritos de Woerner (1997), Condel (1956), Diener (1947) y Valdivia (1947), así como la memoria de Holland (2009) respecto del ingreso de iglesias no católicas a Chile. Este conjunto se

\footnotetext{
${ }^{1}$ Este tema no se desarrollará en el presente texto, pero dada la relevancia del mismo, pueden consultarse detalles en Barrios (2017) y en Serrano (2008), historiadora en cuyo trabajo -particularmente en esta obra- ha tratado en detalle este proceso.
} 
pondrá en diálogo con fuentes secundarias que analizan el desarrollo local en el período que nos ocupa.

Los apartados del escrito expondrán: a) la historia del ingreso y establecimiento de The Alliance en Chile, desde el año 1897 hasta 1905, marcando las temporalidades internas del proceso; b) la identificación de las características de expansión de la misión analizando similitudes, diferencias y formas que adquirió lo que hemos denominado "misión circular" de The Alliance; c) la caracterización del culto y las prácticas misionales y discursivas a partir de la consolidación de la misión; d) un cierre a partir de una síntesis de los resultados.

\section{Ingreso y establecimiento de la misión The Alliance}

La misión The Alliance fue fundada en Estados Unidos por el pastor presbiteriano Albert B. Simpson en 1887. Su filosofía misionera radicó en la visión escatológica del fin de los tiempos como un horizonte cercano. Por tanto, como práctica de fe, promulgaba que la evangelización del mundo debía realizarse en el menor plazo y con el mayor alcance posible (Diener, 1947; Valdivia, 1947; Woerner, 1997). El discurso apostólico se centraba en la conversión de la persona humana, como una experiencia esencial para la salvación (Ospina, 2015). Se trataba de una interpretación soteriológica (ligada a la teología dedicada a la salvación), que rechazaba la predestinación humana y aprobaba que la salvación divina estaba disponible para todas las personas (Campbell, 2012).

La estrategia misionera se declamaba en el eslogan de la misión: "Todo el evangelio para todo el mundo", que implicaba que la práctica misional era parte del dogma. Esto se sintetizó en una imagen (Figura $\mathrm{N}^{\circ} 1$ ). La cruz tenía en el centro un círculo que representaba la figura del planeta, con un gráfico con reminiscencias al continente americano. La idea de la totalidad y centralidad de la figura de Cristo se presentó en cuatro símbolos: Cristo Salvador, Santificador, Sanador y Rey que viene (Forni, Mallimaci y Cárdenas, 2003). En la Figura $\mathrm{N}^{\circ}$ 1, la cruz del extremo superior representa la salvación divina disponible para todas las personas. Al costado derecho se ubica una copa que representa la idea de la santificación como proceso constante del ser humano. En el extremo inferior se ubica un jarrón que simboliza la disponibilidad de la sanidad divina para el ser humano, tanto para su sanación espiritual como corporal. Al costado izquierdo se ve la imagen de una corona que recuerda el inminente y apocalíptico retorno de Jesús a la Tierra (Simpson, 1979).

Figura $\mathbf{N}^{\circ}$ 1: Primer logo representativo de The Alliance en Estados Unidos

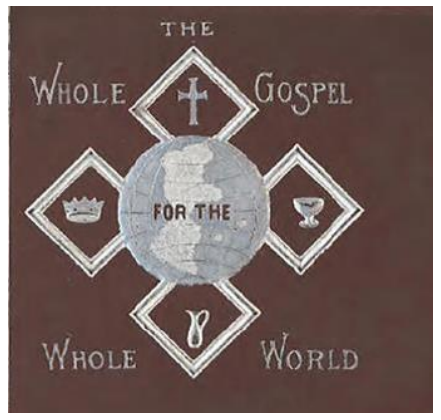

Fuente: Portada del documento The Story of The Christian and Missionary Alliance (1900).

Revista Cultura \& Religión Vol. XIV, 2020 № 1 (julio-diciembre) 
Si bien focalizaremos el avance de esta misión en Sudamérica, y particularmente en Chile, fue un movimiento que se dirigió hacia todos los continentes, por ello el diálogo del caso chileno desde sus inicios se desarrolló a escala global. The Alliance surgió en el marco del tercer gran despertar espiritual que experimentó el protestantismo entre los años 1875 y 1915. Según García (2012), este movimiento se denominó "evangelicalismo", término adoptado por The Alliance en el período que nos ocupa. ${ }^{2}$ Esta misión se caracterizó por el afán evangelizador, enfocado en la defensa de una interpretación literal de la Biblia y en abarcar con su mensaje a las masas de obreros. La Biblia, establecida como texto incuestionable vinculado a una filosofía escatológica premilenialista, se presentó como argumento de la "salvación personal" y no colectiva, diferenciándose de otras iglesias protestantes estadounidenses (García, 2012).

The Alliance desarrolló prácticas evangelizadoras sostenidas en iniciativas personales que se registran en los relatos de la misión. El envío de misioneros a América del Sur fue ideado por Emilio Olssen, un marino sueco convertido al evangelicalismo en Buenos Aires. En 1896, Olssen expuso a Simpson un análisis en el cual afirmaba que la evangelización de la población de esta región podía llevarse a cabo en solo cuatro años. Aquel era "colportor" (vendedor de literatura religiosa), y presentó la experiencia de sus viajes desde Buenos Aires, en Argentina, hasta Bolivia por el norte y por el sudoeste del continente, hasta Valdivia, Chile (Olssen, 1899), para fundamentar la actividad misional en el territorio. A partir de los datos de Olssen se planteó un avance misional muy optimista, desconociendo las tensiones religiosas que existían. Evidencia de ello fue el reporte de nuevos misioneros enviados a América del Sur durante el año 1897:

se hizo una reunión de despedida a la que fuimos [convocados] para que nos informen sobre la salida de otro grupo de misioneros a América del Sur. El principal objetivo del Sr. Emilio Olssen es llevar adelante la apertura de una nueva campaña para la evangelización del continente olvidado. Cinco han tomado la delantera, el Sr. y la Sra. Bailley a Venezuela, el señor y la señora Weiss y el señor Dawson a Chile y ahora otros siete se han ido a otros países. [...] El [nuevo equipo] se compone de doce personas [...] nueve ya están en el campo [...] en América del Sur. (Christian and Missionary Alliance, 14 de mayo de 1897, p. 468) (traducción nuestra)

La salvación personal iba de la mano de la capacidad de salvación de otros. Así, desde el imaginario del fin de los tiempos, se trasladaron hacia lo que ellos entendían como los confines de la geografía, confiados en generar un impacto mediante la prédica de muy pocas personas. El territorio de la fe era una promesa basada en el imaginario de un territorio vacío.

\section{La llegada al sur de Chile. De misioneros independientes a misioneros organizados (1897-1901)}

Los misioneros que llegaron al sur de Chile fueron Albert Dawson, Katherine Zacharias y Henry Weiss. Iniciaban, de este modo, una expansión mayor (Forni, Mallimaci

\footnotetext{
${ }^{2}$ De allí procede el término "evangélico", con características distintivas que lo diferenciaron del protestantismo histórico surgido en la escisión del siglo XVI. Figueroa (2016) trabaja un detalle de la apropiación oficial de este término por parte de los protestantismos norteamericanos establecidos en América Latina en un sínodo desarrollado en Panamá en 1916. A lo largo de este texto no retomaremos esta denominación, pues el culto analizado eligió otra, el "evangelicalismo", como referencia a sí mismos.
} 
y Cárdenas, 2003), cuyo detalle se expone en el Cuadro $\mathrm{N}^{\circ} 1$. Se establecieron entre los años 1897 y 1898, período en que, por conflictos internos, Olssen dejó de dirigir la misión de América del Sur (Shannon, 1997), quedando el plan de evangelización sin un superintendente que dirigiera las acciones de los misioneros enviados a cada país.

En Chile, además de los tres misioneros estadounidenses, se contó con nueve "trabajadores nacionales", que las fuentes no identificaron individualmente. Los pobladores locales no aparecen como "misioneros", sino que se presentan como "native workers"; es decir, como trabajadores nacionales. Esto permite pensar que los misioneros adhirieron a las funciones clericales a personas que no eran parte oficial de la misión ni contaban con estudios religiosos que los validaran en funciones más importantes, pero que en rigor eran colaboradores en la función principal de evangelizar e instalar la empresa misionera en el territorio sur chileno. No existe registro de nombres para la feligresía local, como tampoco para las mujeres reconocidas como esposas, que son referenciadas a través de sus maridos, tal como se observa en el cuadro a continuación: 
Cuadro $N^{\circ}$ 1: Nómina de los misioneros enviados a América del Sur (1897-1898)

\begin{tabular}{|c|c|c|c|}
\hline Nombre & Cargo & Destino & Año ingreso \\
\hline Gerard A. Bailley & Misionero & Caracas, Venezuela & 1897 \\
\hline Sra Bailley & Misionera & Caracas, Venezuela & 1897 \\
\hline Alice C. Wood & Misionera & Caracas, Venezuela & 1898 \\
\hline Albert E. Dawson & Misionero & Victoria, Chile & 1897 \\
\hline Katherine Zacharias & Misionera & Victoria, Chile & 1897 \\
\hline Henry Weiss & Misionero & Victoria, Chile & 1897 \\
\hline $\begin{array}{l}\text { Nueve trabajadores } \\
\text { nacionales }\end{array}$ & Misioneros & Victoria, Chile & 1898 \\
\hline Sr. Clark & Misionero & $\begin{array}{l}\text { Zona de Panamá, } \\
\text { Colombia }\end{array}$ & 1897 \\
\hline W. G. Fritz & Misionero & Guayaquil, Ecuador & 1897 \\
\hline E. B. Tarbox & Misionero & Guayaquil, Ecuador & 1898 \\
\hline Sra. Tarbox & Misionera & Guayaquil, Ecuador & 1898 \\
\hline George Arnold & Misionero & $\begin{array}{l}\text { Poono (Puno) y Callao, } \\
\text { Perú }\end{array}$ & 1897 \\
\hline Frederick E. Mebius & Misionero & Bolivia & 1897 \\
\hline Emilio Olssen & Superintendente & Buenos Aires, Argentina & 1896 \\
\hline Sra. Olssen & Misionera & Buenos Aires, Argentina & 1896 \\
\hline John W. Price & Misionero & La Plata, Argentina & 1897 \\
\hline Sra Price & Misionera & La Plata, Argentina & 1897 \\
\hline Sr. Logan & Misionero & Olavarría, Argentina & 1897 \\
\hline Sra. Logan & Misionera & Olavarría, Argentina & 1897 \\
\hline Joseph Thacker & Misionero & Montevideo, Argentina & 1897 \\
\hline Irving Hathaway & Misionero & Buenos Aires, Argentina & 1897 \\
\hline David Bushanan & Misionero & Buenos Aires, Argentina & 1897 \\
\hline J. B. Emery & Misionero & Buenos Aires, Argentina & 1897 \\
\hline Sra. Emery & Misionera & Buenos Aires, Argentina & 1897 \\
\hline W. D. Smart & Misionero & Barracas, Argentina & 1897 \\
\hline Sra. Smart & Misionera & Barracas, Argentina & 1897 \\
\hline Williams A. Cook & Misionero & Brasil & 1898 \\
\hline Sr. Nelson & Misionero & Brasil & 1898 \\
\hline Sra. Nelson & Misionera & Brasil & 1898 \\
\hline
\end{tabular}

Fuente: elaboración propia a partir de la información de la ediciones de 1898 del periódico Christian and Missionary Alliance).

El cuadro presenta la distribución de los 28 misioneros y misioneras, con sus equívocos. Por ejemplo, respecto de Joseph Thacker, el periódico reconoció la ciudad de Montevideo como parte de Argentina y no de Uruguay. Estos antecedentes solo identifican los nombres, año y ciudades del primer destino de los misioneros. Se omite que algunos fueron redestinados a otras ciudades, tales como Irving Hathaway, que apareció misionando en Asunción, Paraguay (Shannon, 1997), y otros que se retiraron de la misión o retornaron a Estados Unidos. Los cambios son reconocidos en reportes posteriores:

Nuestros misioneros en los campos argentinos (...) en la actualidad están conformados por el Sr. y la Sra. Smart, el Sr. Buchanan y el Sr. y la Sra. Logan, quienes esperan ir pronto a Bolivia. El Sr. y la Sra. Emery han regresado a este país y el Sr. y la Sra. Thacker se han retirado de la Misión. El Sr. Cook es nuestro único representante actualmente en Brasil. El trabajo que anteriormente se realizaba en la provincia de San Paulo en Jahu se suspendió, y los trabajadores fueron trasladados a Buenos Aires. El Sr. Cook regresó durante este año de 
su largo viaje de más de un año, y ha relatado la interesante historia de su visita a las tribus indígenas del interior de Brasil (...) Se reunieron numerosas tribus que lo recibieron con la mayor cordialidad. (Christian and Missionary Alliance, 19 de mayo de 1900, p. 325) (traducción nuestra)

América del Sur fue vista como tierra de infieles, en términos equivalentes a los de las misiones católicas del siglo XVI. Los propios salesianos, a mediados del siglo XIX, plantearon a la Patagonia argentina como "terra ad gentes" (Nicoletti, 2012, p. 185), y desde allí diseñaron una activa práctica misional. Los confines del mundo, aun para un tardío siglo XIX, vuelven a aparecer como los confines de la fe.

Respecto de The Alliance, cabe destacar que los tres primeros misioneros enviados a Chile permanecieron activos hasta 1914 y 1915. Sus historias personales han sido registradas y permiten ver los imaginarios territoriales desde los cuales arraigaron el culto. Albert Dawson llegó a Chile el 19 de abril de 1897; zarpó desde Estados Unidos y arribó al puerto de Talcahuano (Chile) acompañado por Henry Weiss y Katherine Zacharias, un matrimonio menonita que también había sido enviado por The Alliance a Chile (Christian and Missionary Alliance, 1897). Los tres misioneros fueron enviados sin sueldo, por lo que debieron subsistir trabajando y recibiendo eventuales ofrendas de protestantes ya instalados en el territorio sur chileno, por ello hablamos de "misioneros independientes". En el caso de Dawson, este se sustentó con la venta de literatura religiosa (Diener, 1947). No hay mayores datos respecto de las actividades económicas del matrimonio.

Los misioneros decidieron instalarse en el sur chileno, porque en el viaje se encontraron con el misionero presbiteriano William Boomer, que trabajaba en Chile. Este les informó acerca del panorama religioso del país, insinuándoles que el mejor campo para ellos sería el sur, porque no había ninguna organización misionera establecida y porque había muchos alemanes a quienes podían ayudar, particularmente Weiss, que dominaba el idioma (Anderson, 1990; Oyarzún, 1921). Aparentemente, Boomer desconocía que en el sur chileno se encontraba establecida la misión anglicana South American Missionary Society en la ciudad de Lota desde 1861, en Temuco desde 1890 (Zabala, 2008) y en Quepe desde 1893 (Mansilla, Liberona y Piñones, 2016; Menard, 2013;), como también desconocía el establecimiento de comunidades luteranas en Osorno y Puerto Montt, en 1863, y en Valdivia, en 1885.

La acción misional de The Alliance no se vinculó a un culto establecido, sino que los misioneros ingresaron al país como migrantes norteamericanos. No hay antecedentes que Dawson, pastor metodista, haya seguido asociado a los metodistas canadienses, pero Weiss reportaba sus actividades misionales a la Conferencia de los Hermanos Menonitas estadounidenses. Dawson tampoco se asoció a la Iglesia metodista que se había establecido en Chile en 1878. Henry y Katherine Weiss, como menonitas, no tenían ninguna congregación establecida en el territorio nacional. Incluso, las congregaciones que fueron estableciendo tampoco se asociaron a las iglesias que estaban fundadas en Chile, sino que funcionaron de manera independiente, con el apoyo espiritual de los misioneros y sus ayudantes.

Las actividades religiosas, y por tanto el territorio de la fe, fueron instalándose en el espacio doméstico, principalmente en hogares de colonos establecidos en la parte norte de la Araucanía: Traiguén, Victoria, Contulmo y sus entornos rurales, cambiando el mapa de la geografía religiosa en el espacio. La geografía de lo sagrado se mezcla con el espacio vivido, 
un ámbito que, como indica Lerma (2013), incluye procesos que permiten entender las localidades como instancias que forman parte de un espacio complejo, interrelacionado y en transformación, donde la religión se muestra como una variable significativa.

En esa zona ya se encontraban asentadas congregaciones protestantes, pero estas carecían de una organización legal y de una estructura clerical compleja. Se sustentaban en las creencias, ritos y discursos traídos desde sus países de origen. En 1892 ya se había fundado una congregación bautista en la ciudad de Contulmo y, en 1894, en la colonia de El Salto (Condell, 1956; Valdivia, 1947). Todo esto fue conocido por los religiosos norteamericanos recién al llegar.

A su arribo a Chile, los misioneros se encontraron con un territorio tensionado por un proceso de secularización que abría posibilidades a los protestantismos. Barrios (2017) señala que en el país a fines del siglo XIX se dio un proceso de modernidad, ligado a la secularización, que se opuso a la privatización de la religión e invitó a los protestantismos a la conquista de los espacios públicos en un esfuerzo de resacralizarlos. La práctica de The Alliance se sumó a estas disputas y los ataques recibidos pusieron en evidencia los límites legales para el ejercicio libre de los credos (Elgueta, 2018). En 1900 se reportó el avance más significativo en la misión chilena:

En la República de Chile The Alliance tiene cinco misioneros, el [matrimonio] Weiss, el Sr. Dawson y el [matrimonio] Rose. Los Rose se asociaron al trabajo durante el año pasado. Tres provincias están ocupadas (...) Chiloé, Voliva y Osoren (sic) [Valdivia y Osorno]. Hay catorce lugares de culto, un número total de miembros de 238, y con sesenta personas convertidas que esperan ser bautizadas. Treinta y cuatro fueron bautizadas el año pasado. Gran parte del trabajo se realiza entre las tribus indígenas, que están en estrecho contacto con esta Misión. Hay un gran trabajo editorial que lleva a cabo un cristiano nativo, con una impresora [que edita] grandes cantidades de literatura cristiana para distribuirla, incluyendo muchas traducciones de los libros y folletos de The Alliance. La Misión informa $\$ 920.76$ reunidos. Dos importantes reuniones fueron realizadas durante el año, una para los nativos de Quillem, que duró tres días (...) La otra fue para los miembros alemanes (...) que forman un gran asentamiento en este territorio. Un gran espíritu misionero se manifestó entre los acuerdos y se hicieron muchas promesas, incluso de los más pobres, para difundir el evangelio. El trabajo no ha estado exento de [dificultades] y tres de los hermanos nativos fueron encerrados en la cárcel pública durante el año por la predicación del evangelio. (Christian and Missionary Alliance, 19 de mayo de 1900, p. 325) (traducción nuestra)

Este extracto muestra tres cosas. Una, las esposas de los misioneros son reconocidas con un rol equivalente al de sus esposos. Dos, la limitación legal de la práctica de nuevas corrientes religiosas, lo cual devela un alto grado de intolerancia social a pesar del creciente discurso liberal. Tres, el carácter racial de la aplicación de la ley. Los estadounidense no fueron encerrados, a pesar de ser perseguidos, y fueron los chilenos quienes, a los ojos de la ley, aparecieron con una responsabilidad mayor de respeto a la norma.

Más allá de estas dificultades, en las que el martirio sumó prestigio a la labor misional, el reporte da cuenta de que existió un reconocimiento de ocupación territorial entre Valdivia y Chiloé. Sin embargo, en tanto las fuentes remiten a la información que desde Chile se mandaba a Estados Unidos, encontramos que los principales registros refieren a las actividades personales de los misioneros enviados, opacando a actores locales y sus posibles tránsitos. 


\section{Las misiones circulares como inicio y estrategia de establecimiento}

Los primeros dos años de actividad misional se destacaron por su carácter itinerante, que consistía en la atención espiritual de colonos organizados en pequeñas comunidades religiosas mientras extendían sus actividades de evangelización a la población chilena. Este trabajo fue desarrollado tanto por los misioneros como por los propios colonos, que ayudaban en la función apostólica en un circuito que integraba las comunidades organizadas previamente, como El Salto, Colonia de Quillem, Púa, Contulmo, Traiguén y Angol (Woerner, 1997), todas ubicadas en una extensión de $150 \mathrm{~km}$ en torno al sitio de llegada (Ver Figura $\mathrm{N}^{\circ}$ 2).

Figura $\mathrm{N}^{\circ}$ 2: Mapa del circuito sagrado de Dawson

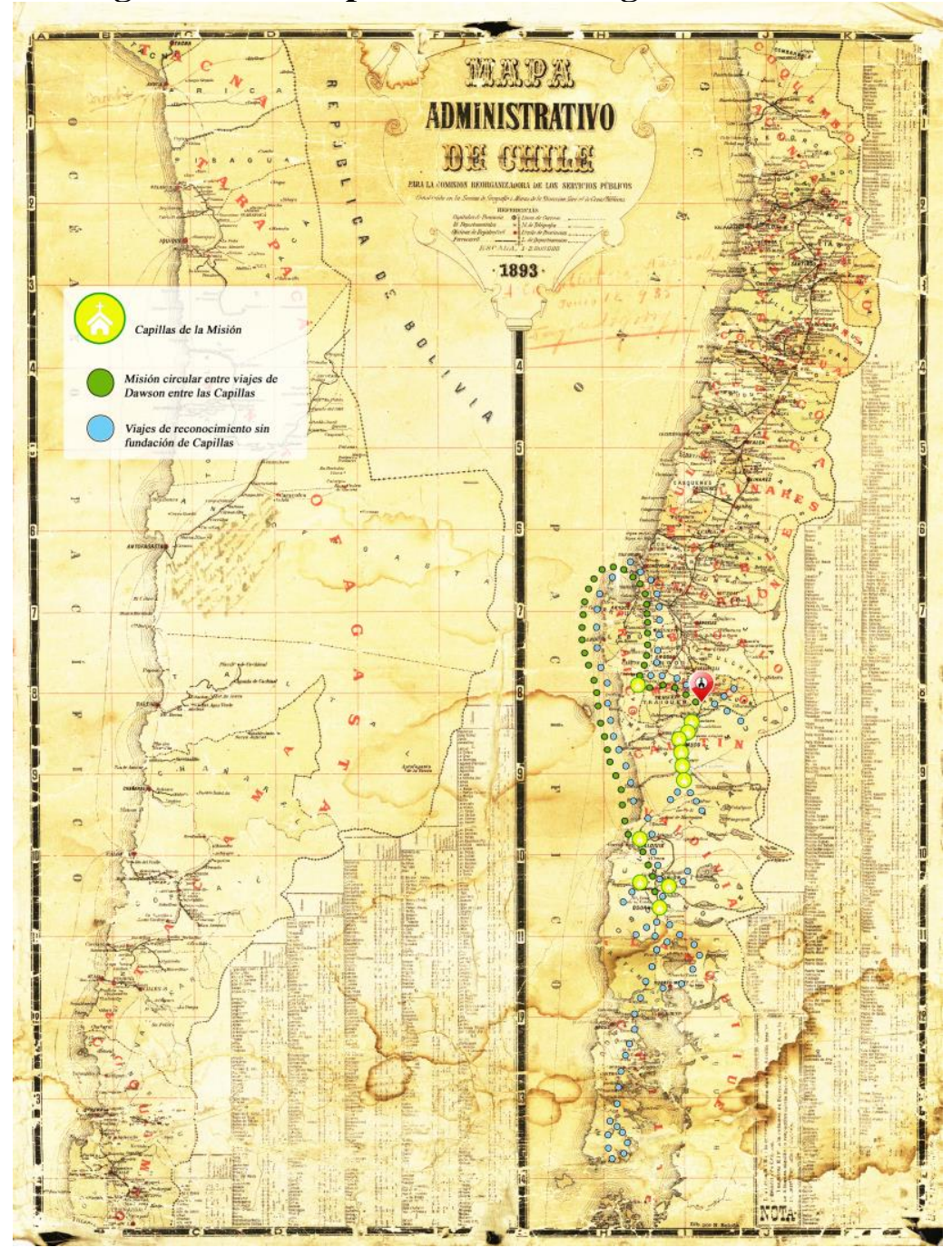

Fuente: elaboración propia a partir de un mapa publicado en el sitio web Memoria Chilena (memoriachilena.gob.cl), ${ }^{3}$ intervenido por el diseñador Cristian Aguas a partir de los datos de las fuentes citadas en el presente artículo.

\footnotetext{
${ }^{3}$ http://www.memoriachilena.gob.cl/602/w3-article-546953.html
} 
Los registros internos dan cuenta del movimiento de los estadounidenses y su tránsito caracteriza el territorio sagrado que se fue instalando. El punto de inicio de los viajes de Dawson y Weiss fue el poblado de Victoria; desde allí enviaban los reportes a Estados Unidos y allí se construyó en 1899 la primera capilla adscrita a The Alliance en Chile, con el apoyo de la familia del colono August Berg (Woerner, 1997). A la luz de construcciones posteriores, podemos pensar que esta primera capilla fue edificada con marcas sutiles que permitían, desde fuera, reconocerla como espacio de fe, aun sin perder la imagen de hogar. El doble rol, de casa y de templo, se percibía en la trabajada fachada y en el detalle de las ventanas, que la alejaban de una casa común, pero tampoco la homologaban a los templos hasta entonces construidos (Ver Figura $\mathrm{N}^{\circ}$ 3).

\section{Figura $\mathrm{N}^{\circ}$ 3: Segunda capilla de la misión The Alliance en la ciudad de Osorno (1906)}

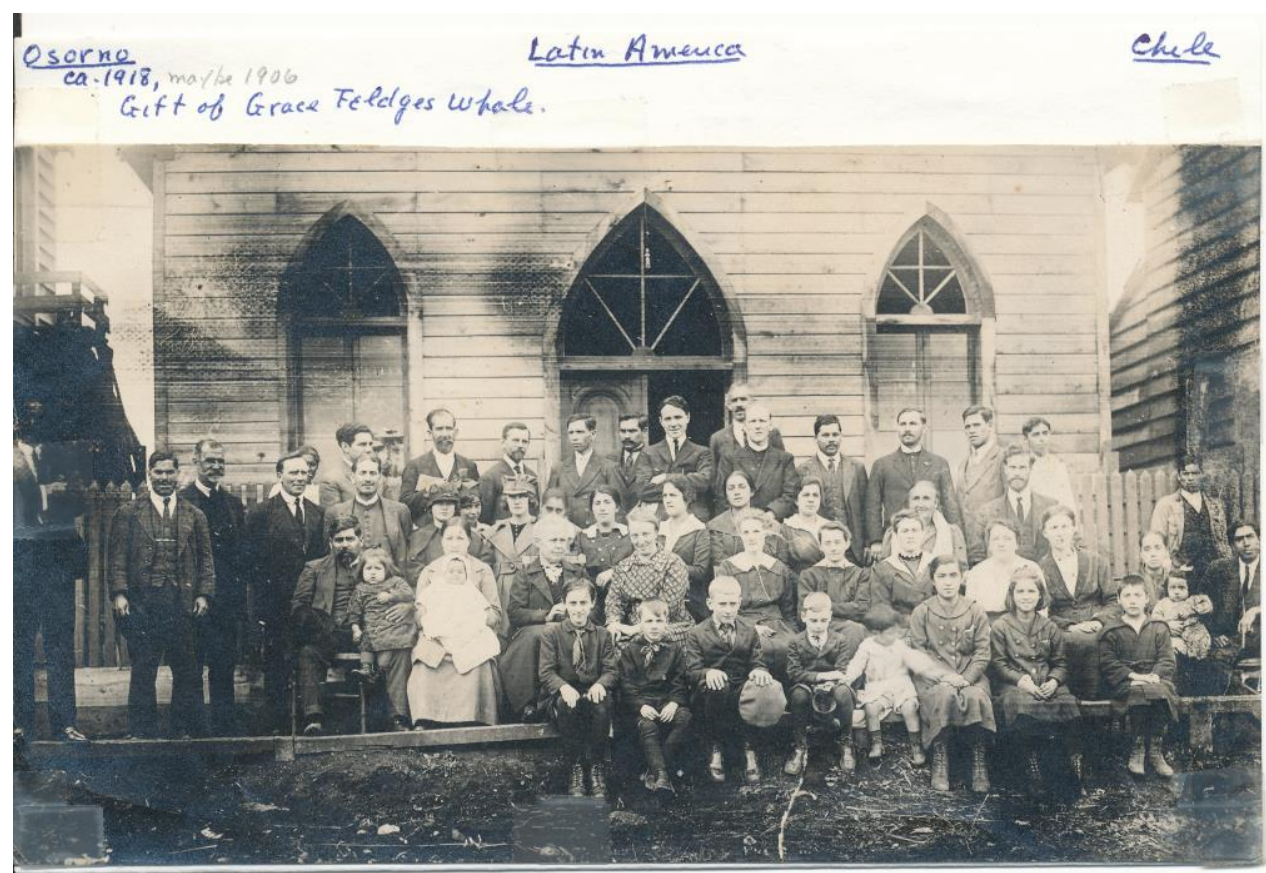

Fuente: Fondo Albert Dawson, sección imágenes, del Archivo Histórico del Sur (Centro de Estudios del Desarrollo Regional y Políticas Públicas de la Universidad de Los Lagos)

A continuación se ofrecen algunos testimonios de las actividades realizadas por los misioneros hacia fines del siglo XIX:

Estuve en Contulmo, a unas sesenta millas de aquí (...) y estuve allí ocho días. Encontré una pequeña comunidad del pueblo de Dios que no podía ponerse de acuerdo debido a una doctrina. El Señor los unió, y tuvimos una gran victoria entre los chilenos y los alemanes. En total había veinticinco convertidos, entre ellos había nueve chilenos. Bendito sea su nombre por siempre. (Christian and Missionary Alliance, 2 de marzo de 1898, p. 212) (traducción nuestra) 
A. E. Dawson. Victoria, Chile. Agradece a la Junta por preguntar sobre sus finanzas y dice que tiene dinero propio y que puede mantenerse a sí mismo. Necesita un ayudante nativo. Es imposible trabajar sin uno de ellos. El gasto para este ayudante será de $\$ 100$ en oro por un año. El trabajo es brillante y alentador.

H. L. Weiss, Victoria, Chile. El Señor está derramando lluvias de bendiciones sobre nosotros con la conversión de muchas almas. Al mismo tiempo estamos recibiendo nuestra parte de persecución. Nos llaman demonios, espiritistas, hechiceros, etc. Algunos parecen tener miedo de estrecharnos la mano (...) hace poco bauticé seis. Reportamos sesenta conversiones durante los últimos dos meses y varios casos de curación. (Christian and Missionary Alliance, 23 de marzo de 1898, p. 283) (traducción nuestra)

En términos geográficos, las actividades misionales iniciales se concentraron en la zona de Victoria y avanzaban en forma radial. La atención espiritual implicaba funciones como la homilía dominical, la instrucción catequística de la población, el bautismo de los feligreses y la celebración de la eucaristía, que llamaban "cena del Señor". La población que más rápido se adhirió a los oficios religiosos fue la de los migrantes europeos, posiblemente porque se encontraban más familiarizados con el protestantismo que la población nacional.

El detalle de la expansión de la práctica religiosa no es algo menor. Las referencias apelan al esfuerzo, e incluso a martirios, que pasan la evangelización por la experiencia personal instituida por la teología.

La lógica diseñada para expandir la práctica religiosa en The Alliance fue dinámica y en varios casos estructuró un modelo de acción muy similar a las misiones circulares que caracterizaron a los jesuitas en el Archipiélago de Chiloé durante los siglos XVII y XVIII (Gutiérrez, 2007; Moreno, 2011).

Los jesuitas atendían todos los años a dispersas comunidades que tenían como referencia fundamental un conjunto de 77 capillas [...] donde, durante tres o cuatro días, impartían la catequesis, bautizaban, casaban y daban la comunión y otros sacramentos. Todo esto requería una adecuada planificación que permitía cumplir acabadamente con la tarea que el Colegio de Castro regenteaba. (Gutiérrez, 2007, p. 52)

El trabajo apostólico de los jesuitas y el trabajo de evangelización de los misioneros de The Alliance tienen características similares en el sentido de cómo fueron pensadas para, en primer lugar, instalarse en el territorio chileno desde lugares estratégicos con el fin de atender la necesidad espiritual de la población adherida a sus cultos. Sin embargo, la cantidad de capillas de The Alliance fue mucho menor a la de los jesuitas - a la citada capilla de Victoria, de 1899, le siguió una capilla en Valdivia, en 1900. Además, las prácticas no se concentraban solo en esos espacios. Se impartía la liturgia y la enseñanza de la fe en las distintas casas de los espacios recorridos. Podemos pensar que la expansión de este credo se recorre más desde las huellas efímeras del movimiento que desde la materialidad tangible de sus capillas, las cuales no terminan de distinguirse desde su arquitectura, ni se encuentran en sitios emblemáticos de las localidades (Escobar y Núñez 2018). Las construcciones y los hogares de la feligresía que se sumaban, se plantean como espacios de prácticas de culto, con un punto de partida y de retorno en la estación de Victoria.

Como se indicó, el "circuito sacro" de The Alliance fue planificado por Dawson, quien al buscar lugares donde su prédica fuese mejor aceptada, tomaba estos como emplazamientos para instalar una nueva estación misionera. Tal fue el caso de la ciudad de 
Valdivia, Río Bueno, La Unión, Purén y Pitrufquén durante los primeros años de trabajo en Chile. La causa para considerar la misión circular como una estrategia de evangelización fue justamente el planteo de círculos de recorridos, no apoyados en capillas, pero sí en casas de quienes se sumaban a la fe.

Este diseño, antes que con el antecedente jesuita, posiblemente se vincule a la carencia de misioneros. Esto provocaba que Dawson y Weiss debieran desplazarse entre las comunidades existentes para fortalecer su establecimiento y dar atención religiosa. En este punto resultan similares a los de la experiencia jesuita, porque los viajes eran planificados y tenían por objetivo la atención espiritual de sus seguidores a partir de la entrega de la homilía, los bautismos y otras devociones, tales como la celebración de los oficios religiosos o la enseñanza de la biblia (Diener, 1947; Woerner, 1997).

En esta movilidad se reconoce la práctica de la prédica, que a su vez marca diferencia con la de los luteranos, que se instalaron en torno a capillas; o a la práctica católica de fines del siglo XIX, organizada en torno a iglesias establecidas. The Alliance se construyó desde el orden doméstico, ámbito desde el cual se plantea la reflexión introspectiva e individual en torno a la salvación. Los antecedentes revisados dan cuenta de que los viajes de visita entre las colonias eran sistemáticos. Las colonias más cercanas eran visitadas con mayor regularidad, llegando inclusive a visitas semanales.

Es claro que esta movilidad provocaba gastos. En el caso de Dawson, su fuente financiera era la venta de literatura religiosa. Este misionero llegaba hasta Concepción (Diener, 1947; Woerner, 1997) y retornaba a la estación de inicio: Victoria. Por esta capacidad económica, fue Dawson quien llevó adelante el diseño y ejercicio de la mayor parte de los viajes. La búsqueda de nuevos lugares para establecer la misión se hizo a partir del reconocimiento hacia la zona sur. En 1898, Dawson y Weiss viajaron hacia el poblado de Temuco buscando al misionero canadiense Charles Sadleir, quien se había instalado unos años antes entre la población mapuche de los sectores de Chol Chol y Quepe (Kepe). Lamentablemente no lo encontraron (Christian and Missionary Alliance, 1898).

Esta búsqueda nos habla de una fe flexible, ligada a diferentes movimientos evangélicos (metodistas, bautistas, presbiterianos, etc.), a partir de los cuales se planteaba una prédica que, crecientemente, fue entendiendo como antagónica a la feligresía católica. "En Chile tenemos dos estaciones y cuatro misioneros, el Sr. y la Sra. Weiss en Victoria y los Sres. Dawson y Rose en Valdovera (sic). Ha habido muchos bautismos y pruebas alentadoras de la obra del Señor durante la guerra" (Christian and Missionary Alliance, mayo de 1899, p. 178). Esta cita reconoce a Katherine Weiss en forma equivalente a sus colegas varones. Scholtus (2020) analiza cómo las esposas de los misioneros resultaron mujeres empoderadas hasta las primeras décadas del siglo XX. Además de esta mujer recién mencionada, el trabajo misional se consolidó con colaboradores locales, como Wenceslao Valdivia, quien cooperó con The Alliance hasta 1908 (Diener, 1947), aunque su nombre no figura en el registro periodístico. Ello permite reconocer que el periódico aliancista eclipsó la base local de esta iglesia. Un aspecto no menor, en tanto se trató de poblaciones sociales vulnerables. Respecto a estas, The Alliance fue un culto desde el cual poblaciones subalternizadas encontraron vías alternativas de integración social, sobre todo por el incremento de la autoestima vinculada al encuentro con esta fe (Valdivia, 1947), pero esto se omite en la fuente norteamericana.

El año 1899 fue de avances evangelizadores y de reorganización en The Alliance. Primero porque Dawson fundó en octubre una pequeña comunidad religiosa en la ciudad de 
Valdivia, con no más de 15 personas, inmigrantes y chilenos, que actuó como base para la naciente iglesia evangélica de Valdivia (Diener, 1947). Además, incorporó al misionero bautista escocés Williams MacDonald, expandiendo así el trabajo misional y el circuito de evangelización de The Alliance, sin dejar de atender las congregaciones previamente establecidas (Condell, 1956; Diener, 1947; Woerner, 1997).

La incorporación de MacDonald favoreció el trabajo misional. Dawson, que había fundado la congregación de Valdivia durante 1899, comenzó a hacer nuevos viajes de reconocimiento en búsqueda de lugares para establecerse, llevando a cabo un trabajo mixto entre sus actividades de venta de literatura religiosa y de misionero. Así señala:

Salí de Victoria el 28 de octubre y durante los cinco meses de trabajo hasta el 22 de marzo, visité unas veinticinco ciudades. Vendí unos 3.000 libros, que incluyen Biblias, Testamentos, Evangelios y otros libros religiosos. También entregué aproximadamente, 100.000 tratados. Visité muchas de estas ciudades dos o tres veces y también viajé por una gran parte de la zona minera. Como estaba solo, no tenía servicios (religiosos) en todas estas ciudades, pero sí lo hice con un asistente para predicar el Evangelio en unas ocho ciudades donde nunca, o rara vez, se había predicado antes. Veinte o más de las pocas ciudades, que comprenden una población de unos setenta mil, no tienen misiones ni misioneros. Muchas veces me sentí triste por no tener a nadie que me ayudara, tuve que dejar muchas almas inquietas y apurarme para alcanzar a entregar la Palabra de Vida en las zonas más lejanas...

En relación a las perspectivas del trabajo en el futuro, diría que ya hemos abierto el trabajo aquí, que está a unas cien millas al sur de Valdivia, mi antigua estación, donde está ahora el hermano Weiss. También tenemos la intención, si somos financiables, de abrir algunos trabajos en otras dos ciudades vecinas, donde hemos estado y nos han dado mucho ánimo. Me quedaré aquí durante la temporada de lluvias (...) y con el regreso del verano espero hacer más trabajo bíblico. Podría emplear un ayudante para el trabajo, si hubiera alguno de los queridos muchachos en casa que quisiera salir, confiando en Dios y dispuesto a hacer lo que pueda. Durante este verano pagué mis propios gastos con mis ganancias, y también gané unos 150.0. (Christian and Missionary Alliance, 11 de agosto de 1900, pp. 76-77) (traducción nuestra)

El testimonio de Dawson muestra que tenía suficientes ganancias para sostenerse a sí mismo y a otra persona que deseara trabajar en Sudamérica. La ciudad en que posiblemente estuvo evangelizando fue Puerto Montt, aludiendo a la distancia de al menos 170 kilómetros al sur de Valdivia. También mencionó su interés en dos ciudades más cercanas a su antigua estación, posiblemente La Unión y Río Bueno, donde se radicó posteriormente para fundar nuevas comunidades religiosas. Dado los intereses de Dawson, el matrimonio Weiss debió trasladarse de Victoria a Valdivia a fines de 1899, para fortalecer la congregación que había sido fundada y permitir que Dawson continuara con sus viajes exploratorios.

Entre 1897 y 1900 Dawson amplió el territorio de la fe de esta congregación realizando visitas a la mayoría de los poblados de la zona minera aledaña a Concepción llegando hasta la Patagonia, en Punta Arenas. Trazó, a partir de la experiencia de sus viajes, un circuito regular, marcado y circular del trabajo misional de The Alliance. Su ingeniería apostólica, vinculada a su afán evangelizador -anclado en sus prédicas y sus folletos religiosos- favoreció el establecimiento de nuevas comunidades y, en consecuencia, de nuevas estaciones de la misión norteamericana en el territorio chileno. 
Como se mencionó anteriormente, el ingreso de MacDonald permitió la reorganización de los trabajos de los misioneros:

MacDonald tuvo a su cargo el sector comprendido entre Gorbea y Púa, y fue precisamente en ese sector donde se hicieron sentir más las doctrinas bautistas, por influencia de MacDonald y porque muchos de sus primeros convertidos lo fueron por obra de los bautistas alemanes. (Condell, 1956, p. 50)

El misionero escocés recibió un terreno fiscal en la zona de Freire, donde se estableció con su familia y fue su centro de operaciones para visitar las emergentes comunidades religiosas de Temuco, Cajón, Mune, Huilío, Pitrufquén y Gorbea (Condell, 1956; Diener, 1947). Se destaca que su esposa no es mencionada como misionera. Por su parte Weiss quedó a cargo de Valdivia y su trabajo principal fue dedicar tiempo a sus actividades de imprenta, consolidar la comunidad fundada por Dawson y finalizar la construcción de la capilla, que fue inaugurada en octubre de 1900. En tanto Dawson se encargó de establecer nuevas comunidades religiosas y capillas hacia el territorio del sur chileno.

A partir de 1901, la ciudad de Valdivia representó el centro de operaciones de The Alliance, lo que ocasionó el establecimiento de la mayor cantidad de misioneros y colaboradores para trabajar en el lugar: Dawson, el matrimonio Weiss, el matrimonio Rose, los colonos colaboradores Joseph Schmidlin y Wilfred Diener, y los colaboradores Wenceslao Valdivia, Manuel Aburto Panguilef y David Mancilla (Diener, 1947; Woerner, 1997). Ese mismo año se constituyó el comité ejecutivo de The Alliance en Chile, llamado "The Board", el cual fue constituido sólo por los representantes de la misión norteamericana, aunque después sumaron a MacDonald y Diener. Este acto resolvió la inexistente estructura clerical de la misión en Chile y, posiblemente, fue un acto de urgencia a causa de que el cargo de superintendente para Sudamérica estaba vacante tras el retiro de Olssen. El informe de los misioneros para mayo de 1901 fue:

Aquí tenemos tres estaciones y cuatro misioneros, el matrimonio Weiss, el Sr. Dawson y el Sr. MacDonald (...) El trabajo ha sido visitado con un avivamiento precioso durante el año pasado y se bautizaron sesenta y cinco (...) La membresía total es ahora de 270. El hermano Weiss informa una serie de casos valiosos de curación, una hermana completamente paralizada por un lado, pero con un gran deseo de ser bautizada, se levantó e insistió para bautizarse (...) ahora se está recuperando rápidamente. El Sr. Dawson se ha dedicado al trabajo de evangelización y ha abierto tres estaciones, una de ellas especialmente bendecida, Río Bueno, donde se formó una iglesia de veinte miembros y, a pesar de la amarga persecución, el trabajo es muy esperanzador. Las iglesias en Chile contribuyeron con \$ 368.00 además de los medios privados de los misioneros utilizados libremente en el trabajo. El trabajo en Chile se lleva a cabo entre los españoles, los alemanes y los indígenas. (Christian and Missionary Alliance, 4 de mayo de 1901, p. 250) (traducción nuestra)

Los alentadores resultados que arrojó el trabajo apostólico de los misioneros de The Alliance durante 1900 se reflejaron en el aumento de población inscrita a su nueva propuesta religiosa que, para ese año, sumó 270 personas. El principal logro alcanzado fue la fundación de otra congregación en la ciudad de Río Bueno, a partir del trabajo permanente de Dawson, quien simultáneamente coordinaba los viajes de visita a La Unión y Osorno. 
El reporte que se transcribió anteriormente fue anunciado en Estados Unidos como parte de un revival que se estaba gestando en el sur chileno, tanto por el notable aumento de prosélitos como de los variados "casos notables de curaciones", los cuales fueron aumentando según se iba difundiendo la prédica de los misioneros.

El año 1901 trajo la fundación final de la comunidad religiosa de La Unión, un poblado que regularmente fue visitado por los misioneros, pero sin muchos resultados iniciales. Dawson reportó que:

Ahora estoy tranquilo de nuevo para el invierno en La Unión. Tenía una casa alquilada aquí durante el verano pero no la ocupaba mucho. Estaba a punto de abandonar esta ciudad, ya que parece un lugar difícil, pero últimamente un buen número ha venido a los servicios, por lo que me alienta a esperar un poco más para ver si nuestra siembra germina y produce.

El suelo es muy duro, de hecho, gran parte es 'roca incrédula'. En esta parte de Chile hay una gran influencia alemana, que, si bien ha provocado la libertad de las religiones, también ha ocasionado incredulidad e infidelidad. La mayoría de los alemanes nacidos en el país se ríen de la religión y se burlan de la fe de sus padres, y los chilenos siguen rápidamente sus pasos. (Christian and Missionary Alliance, 11 de enero de 1902, p. 19) (traducción nuestra)

Respecto de la zona previamente evangelizada, de la cual se encargó MacDonald, la estación principal fue su propia casa, ubicada cerca del poblado de Freire. Desde allí hizo un circuito similar al de Dawson, pero a diferencia de este, el establecimiento de congregaciones estuvo marcado por las migraciones internas de los colonos, vale decir, mayormente por personas evangelizadas o, al menos, participantes de comunidades religiosas previamente establecidas y no por la adhesión de otras personas. De este modo, MacDonald visitó activamente las nacientes congregaciones a su cargo (Diener, 1947). No se logró constatar que MacDonald haya fundado alguna estación, pero sí puede afirmarse que Dawson, antes de retornar a Estados Unidos, apoyó la construcción de una nueva capilla en el poblado de Pitrufquén. "Con alegría puedo anunciar que construimos una pequeña capilla en Pitrufquén, capaz de albergar entre 150 a 175 personas. Fue inauguradael 13 de abril, gran parte del trabajo fue realizado por mis propias manos" (Christian and Missionary Alliance, 23 de agosto de 1902, p. 100).

Si pensamos en las variables en torno a las cuales se reflexiona para definir el establecimiento misional, encontramos tres elementos desde los cuales se configura el territorio de la fe (Rodrigues, 2016): (i) la distancia, que debía ser lo mayor posible, pero a la vez accesible respecto de las viviendas de los misioneros; (ii) la generación de dinero para la subsistencia de los misioneros, como condición de posibilidad de las prácticas y (iii) el número de pastores formados reconocidos como tales por los norteamericanos, que incidía en el diseño de la prédica. En este período la fe se practicaba en los espacios domésticos y estos establecían las marcas de resignificación. La disputa de espacios públicos, reconocida por Barrios (2017), comenzó desde hogares, de misioneros y de fieles, que puede pensarse como la base del sentido del territorio vivido (Lerma, 2013). Las capillas aparecen más como un objetivo que como un logro efectivo. La energía puesta en las misiones circulares y el éxito considerado en esta lógica de expansión evidencian una estrategia diferente a la disputa de los espacios públicos urbanos, aspecto que será modificado cuando se considere establecida la misión. 


\section{La misión establecida: 1901-1905}

Las fuentes revisadas dieron cuenta de un circuito sagrado establecido por The Alliance que, en sus primeros cinco años, se pudo resumir en las siguientes comunidades establecidas (Ver Cuadro $\mathrm{N}^{\circ} 2$ ):

\section{Cuadro $\mathrm{N}^{\circ}$ 2: Comunidades religiosas asociadas a la misión The Alliance (período} 1897-1905)

\begin{tabular}{|c|c|c|c|c|}
\hline Ciudad & Calidad & Fundación & Fundador (es) & Instalaciones \\
\hline Victoria & Estación & 1898 & $\begin{array}{l}\text { Dawson, Weiss, } \\
\text { Zacharias, Berg }\end{array}$ & Templo \\
\hline Valdivia & Estación & 1899 & Dawson, Ross & Capilla \\
\hline Río Bueno & Estación & 1900 & Dawson & Culto doméstico \\
\hline La Unión & Estación & 1900 & Dawson & Culto doméstico \\
\hline Osorno & Lugar de prédica & 1900 & $\begin{array}{l}\text { Dawson, Mansilla, } \\
\text { Schmidlin }\end{array}$ & Culto doméstico \\
\hline Freire & Estación & 1900 & MacDonald & Culto doméstico \\
\hline Pitrufquén & Estación & 1902 & MacDonald & Capilla \\
\hline Cajón & Lugar de prédica & 1900 & MacDonald & Culto doméstico \\
\hline Gorbea & Lugar de prédica & 1900 & MacDonald & Culto doméstico \\
\hline Púa & Lugar de prédica & 1900 & MacDonald & Culto doméstico \\
\hline Contulmo & Estación & 1892 & $\begin{array}{l}\text { Se encontraba } \\
\text { establecida }\end{array}$ & Templo \\
\hline Purén & Estación & 1903 & $\begin{array}{l}\text { Dawson, Matrimonio } \\
\text { Sandoval-Albornoz, } \\
\text { familia Saravia }\end{array}$ & Culto doméstico \\
\hline
\end{tabular}

Fuente: elaboración propia a partir de la información del periódico Christian and Missionary Alliance (18981905).

Los templos se edificaron desde los hogares de los misioneros, cruzando lo sacro con lo doméstico. Su arquitectura resulta un poco más trabajada y en su interior consideran salones amplios para el encuentro de los fieles. Al igual que las capillas, las memorias remiten a lo que transcurre dentro, más que al lugar.

En 1902, Dawson viajó a Estados Unidos, donde expuso los logros y dificultades que tuvieron al ingresar y establecerse en Chile. Sus principales intervenciones fueron en la Convención de Nyack (Nueva York), donde expuso ante los representantes de la misión norteamericana el estado religioso en el que se encontraba la población chilena, pero ya no haciendo referencia al esfuerzo de misionar, sino mostrando tensiones establecidas con los cultos hegemónicos del territorio:

El Sr. Dawson, quién (sic) regresó recientemente de América del Sur, tiene una imagen muy gráfica del culto idólatra de los católicos romanos en ese ignorante país. Leyó el décimo capítulo de los romanos y comparó al romanista de América del Sur con aquellos de los que Pablo estaba escribiendo. "Tienen un celo, pero no según el conocimiento" "de hecho", dijo, "su celo avergonzaría a muchos cristianos. Nada es demasiado difícil para ellos si se hace en nombre de los santos o de la iglesia. Tienen numerosas procesiones durante el año, y la descripción de una es la muestra idéntica de las otras. (Christian and Missionary Alliance, 21 de junio de 1902, p. 354) (traducción nuestra) 
Dawson evaluó las prácticas católicas desde su teología metodista y, en ese marco, su intolerancia a estas devociones emergió con mayor claridad que durante el período de establecimiento, al situarlas en el lugar de la "ignorancia". Cambió su relato, corriéndose de la referencia al ataque para dar cuenta del error de fe del otro. Su erudición metodista le permitió elaborar un manual de pruebas para "contradecir las falsas doctrinas de la Iglesia católica romana" (Woerner, 1997, p. 29) establecida en Chile. Así reportó:

la horrible corrupción social y política, y el carácter formal y degradado de su religión bajo influencia católica. Narró la introducción del evangelio, su obra de tratados y colportaje, y el triunfo del evangelio en muchas almas, cerrando con la súplica por los hombres y los medios y oraciones por los grandes y necesitados campos entre españoles e indígenas. (Christian and Missionary Alliance, 28 de junio de 1902, p. 378) (traducción nuestra)

Las críticas resultan un giro argumental que podemos entender como un punto de inflexión en la forma de la prédica. Ya no se trataba de un territorio vacío de fe, con población a salvar, sino de una disputa de fe con actores presentados como antagónicos.

Las intervenciones de Dawson siguieron con el mismo tono en la Convención de Old Orchard en 1902 (Christian and Missionary Alliance, 16 de agosto de 1902) y en la Convención de South Fork durante noviembre de 1903. Es posible que la intención de Dawson en las convenciones fuera promover el interés en el trabajo misional en el territorio chileno, pues luego de sus reportes fueron enviados dos refuerzos durante 1902: Elise Aeby, una joven enfermera recientemente graduada del seminario misionero de Nyack, y Sarah Klahr, una joven profesora de una iglesia metodista canadiense. A diferencia de las esposas de los pastores, analizadas por Scholtus (2020), las mujeres convocadas eran solteras, y tenían capacidad y autonomía para mantenerse.

El territorio de la fe, establecido desde el tránsito y los espacios domésticos, suma acciones de misioneras que, como mujeres solteras, disputan espacios públicos de prédica en un ejercicio que en sí discutió y amplió los espacios sagrados instituidos en las localidades del sur de Chile (Escobar y Núñez, 2018). La ausencia de Dawson y la necesidad de atender las comunidades fundadas propiciaron la incorporación de ayudantes para sumarlos a la básica estructura clerical que habían establecido en Chile durante 1901. Así se sumó al clero el colono Wilfred Diener, en 1903. Su llegada afianzó los viajes exploratorios hacia el norte y el sur del territorio chileno, junto con sistematizar las primeras memorias de la misión en el país.

La dinámica de misión circular dejó de expandirse en estos años, dado que el "circuito sacro", establecido por Dawson, no fue modificado significativamente a pesar del ingreso de nuevos misioneros y misioneras. La señorita Aeby misionó sola en el poblado de Purén (Christian and Missionary Alliance, 20 de febrero de 1904), y se incrementaron las visitas a Chiloé.

La constitución de comunidades evangelicalistas, la presencia de misioneros y la instalación de capillas y templos adscritos a The Alliance se ampliaron a inicios del siglo XX en el sur chileno, cuando la prédica avanzó en el tono crítico ya expuesto por Dawson en Estados Unidos. Así, se produjo entonces un cambio teológico vinculado a nuevas formas de marcar y disputar territorios. Este giro dio inicio a persecuciones por parte de las poblaciones locales hacia una misión instalada desde hacía cinco años, que ahora se presentaba como 
ilegal y antagónica con más fuerza. Estas persecuciones fueron resultado de un contexto de tensiones religiosas en que el catolicismo estaba perdiendo hegemonía a causa del ingreso de corrientes religiosas protestantes que comenzaban a tener cada vez más relevancia (Barrios, 2017; Escobar, 2014; Serrano, 2008). Así, una prédica que agregaba una crítica directa fue respondida con particular virulencia (Escobar, 2020). Golpizas, quema de capilla, malos tratos, encarcelamientos, se reconocen entre las denuncias que crecieron a partir de 1902.

El ataque a espacios de prédica, como las capillas, se acentuó en las ciudades y poblados más extremos del "circuito sacro" del trabajo misional de The Alliance. Por ejemplo, en la ciudad de Río Bueno, lugar donde se encontraba trabajando la misionera Elise Aeby, se rememora:

El miércoles por la noche en nuestro servicio, como de costumbre, escuchamos a algunos de los enemigos que permanecían en el exterior. Casi treinta personas asistieron a la reunión... Cuando una parte de ellos llegó al centro de la calle, para evitar el lodo a los lados, dos tipos a caballo con un lazo entre ellos, corrieron repentinamente detrás de ellos a una carrera, y tiraron a doce de ellos al suelo. Otro siguió y pisoteó sin sentido los cuerpos postrados. El resultado fue lo suficientemente terrible... Dos fueron heridos en la cabeza, uno de ellos una anciana, que perdió una gran cantidad de sangre, pero fue la más fuerte de todos para soportar el sufrimiento. Un joven tenía la clavícula rota. El resto estaba más o menos golpeado y maltratado. Los tres que fueron heridos más seriamente fueron ayudados por los demás para recibir atención en la capilla. Luego todos se fueron a sus casas.

Según las leyes de Chile, estos malos podrían ser castigados severamente, y como todos fueron reconocidos, y se escuchó alardear de su acto de crueldad, parece que el castigo sería seguro, pero el líder de la pandilla es rico, lo que significa poder e influencia sobre la justicia, por lo que no esperamos verlos castigados. Dos fueron arrestados, para que sean castigados. No obstante, algunos de nosotros nos hemos reunido en el señor "Listos para el servicio o sacrificio". (Christian and Missionary Alliance, 19 de agosto de 1905, p. 520) (traducción nuestra)

Estas dificultades se incrementaron con el correr del siglo XX. Por lo general, todos los misioneros y representantes del protestantismo tuvieron vivencias similares durante el proceso de establecimiento de sus respectivas congregaciones (Diener, 1947; Escobar, 2014; Escobar y Núñez, 2018), lo cual nos permite inferir un punto de inflexión en el inicio del siglo. Adicionalmente cabe destacar que los ataques más duros se dieron en el territorio en donde trabajaba Elise Aeby, y no nos parece menor que el ataque se haya perpetrado en donde una mujer disputaba el derecho a la prédica. Representaban cambios que se planteaban a una sociedad conservadora, donde tanto la fe como la jerarquía social estaban en disputa (Barrios, 2017), en un territorio que se resignificaba desde los propios cultos que superponían sentidos antagónicos en el tránsito de la fe.

\section{Reflexiones finales}

A partir de los relatos de los misioneros interpelamos, desde la geografía de la religión, los orígenes de una apertura religiosa ilegal y castigada que antecede en mucho a la decisión de 1925 de separar la Iglesia del Estado. En ellos encontramos modalidades diferentes de construcción de territorios de fe. En este punto apelamos a la idea de Harvey 
(1998) acerca del territorio como estructura social configurada desde relaciones de poder, que conforma espacios diferenciales de acuerdo a vivencias y trayectorias.

No tenemos registros de todas las trayectorias, solo hemos reconocido la de los misioneros norteamericanos que contaban con fondos como para dejar sus registros en las memorias. Ello no quita mérito al esfuerzo de estos migrantes, pero claramente deja trazas incompletas. Sin embargo, las trayectorias descritas permiten ver que iban a consolidar la estructura de una práctica de fe, que a su vez disputaba espacios de religión, y que redundaron en una persecución y en la negación de ocupación de espacios públicos.

Sin embargo, también permite ver que existió una modalidad previa a este enfrentamiento, aunque no carente de persecuciones. La "misión circular" es el ejemplo. En este punto, el caso introduce un aspecto a considerar: cada fe construye imaginarios territoriales. En una región donde se constataron variadas parcialidades hegemónicas en términos de fe, los luteranos y los católicos se presentaron desde construcciones de territorio destacables. Contrariamente, el territorio de The Alliance se desplegó como un rizoma, con líneas móviles, muchas veces imperceptibles, edificadas en el opaco territorio del ámbito doméstico.

Nos referimos a un nuevo orden, que se pretende exclusivamente religioso, que supone la urgencia del fin de los tiempos y que se solapa a otros ordenamientos que, en cuanto el culto se establece, devienen en antagónicos. Por ello registramos la búsqueda de alternativas en la construcción del territorio, donde la exploración, esto es, el movimiento permanente, resulta en el éxito de la constitución. Es el tránsito, antes que las capillas que son atacadas, el anclaje de la práctica, conformando de este modo una trama, cada vez más densa, de evangelismos que se fueron estableciendo y afianzado en Chile.

\section{Referencias bibliográficas}

Anderson, J. (1990). Historia de los bautistas. Tomo III. Texas: Casa Bautista de Publicaciones

Barrios, A. (2017). El pentecostalismo chileno como respuesta a los cambios secularizadores del siglo XIX. Una mirada en retrospectiva. Cultura y Religión, 11(1), 129-148.

Campbell, T. (2012). Doctrinas metodistas, los fundamentos. Nashville: Abingdon Press.

Camus, M. (2001). Tendencias en la historiografía eclesiástica chilena. Hispania Sacra, 53(108), 589-604.

Carballo, C. y Flores, C. (2019). Geografías de lo sagrado en la contemporaneidad. Bernal: UNQui.

Collier, S. (2005). La construcción de una república 1830-1865. Política e ideas. Santiago: Ediciones Universidad Católica de Chile.

Condell, E. (1956). Guillermo McDonald, el apóstol de la frontera. Santiago: Organizaciones Femeninas Bautistas de los países hispanoamericanos.

Christian and Missionary Alliance (14 de mayo de 1897). Christian and Missionary Alliance, $18(20), 468$.

Christian and Missionary Alliance (2 de marzo de 1898). Christian and Missionary Alliance, 20(9), 212.

Christian and Missionary Alliance (23 de marzo de 1898). Christian and Missionary Alliance, 20(12), 283. 
Christian and Missionary Alliance (mayo de 1899). Christian and Missionary Alliance, 22(6), 178.

Cristian and Missionary Alliance (1900). The story of The Christian and Missionary Alliance. Recuperado de https://www.cmalliance.org/resources/archives/downloads/miscellaneous/story-ofthe-cma.pdf

Christian and Missionary Alliance (19 de mayo de 1900). Christian and Missionary Alliance, 24(20), 325.

Christian and Missionary Alliance (11 de agosto de 1900). Christian and Missionary Alliance, 25(6), 76-77.

Christian and Missionary Alliance (4 de mayo de 1901). Christian and Missionary Alliance, 26(18), 250.

Christian and Missionary Alliance (11 de enero de 1902). Christian and Missionary Alliance, 28(2), 19.

Christian and Missionary Alliance (21 de junio de 1902). Christian and Missionary Alliance, $28(25), 354$.

Christian and Missionary Alliance (28 de junio de 1902). Christian and Missionary Alliance, $28(26), 378$.

Christian and Missionary Alliance (16 de agosto de 1902). Christian and Missionary Alliance, 28(7), 95.

Christian and Missionary Alliance (23 de agosto de 1902). Christian and Missionary Alliance, 29(8), 100.

Christian and Missionary Alliance (20 de febrero de 1904). Christian and Missionary Alliance, 32(11), 173-175.

Christian and Missionary Alliance (19 de agosto de 1905). Christian and Missionary Alliance, 24(32), 520.

Diener, W. (1947). Medio siglo de testimonio para Cristo. Obra de la Alianza Cristiana y Misionera en Chile. Temuco, Chile: Alianza.

Elgueta, R. (2018). "El "despojo de los cementerios": origen y desarrollo de la secularización de la muerte en Chile y la ciudad de Concepción (1871-1884). Hispania Sacra, 70(142), 629-648.

Escobar, D. (2014). Persecuciones religiosas en el sur de Chile. Espacio Regional, 2(11), $131-138$.

Escobar, D. (2020). El proceso de secularización de la sociedad chilena. El caso de la ciudad de Osorno y la instalación de la Misión The Christian and Missionary Alliance. 18981925. (Tesis para optar al grado de Magíster en Ciencias Humanas). Universidad de Los Lagos, Osorno, Chile.

Escobar, D. y Núñez, P. (2018). La apropiación religiosa del imaginario sureño en Chile. El caso de los misioneros aliancistas en Osorno, 1898-1922. En P. Núñez, A. Núñez, B. Matossian, M. Tamagnini y C. Odone (comps.), Araucanía. Nortpatagonia II (pp. 5378). Bariloche: Editorial UNRN.

Figueroa, H. (2016). El protestantismo colombiano: sus orígenes, luchas y expansión (18561991). Cultura y Religión, 10(1), 66-87.

Forni, F., Mallimaci, F. y Cárdenas, L. (2003). Guía de la diversidad religiosa en Buenos Aires. Buenos Aires: Editorial Biblos. 
García, F. (2012). Protestantes, evangélicos y pentecostales: aclaraciones conceptuales preliminares en un campo de investigación social. Folios, 36, segundo semestre, 171$187 . \quad$ Recuperado de https://revistas.pedagogica.edu.co/index.php/RF/article/view/1731/1680

Govea, A. (2016). La construcción simbólica del territorio a partir de la religiosidad. El caso de las fiestas patronales de la Chontalpa, Tabasco, México. Cultura y Religión, 10(2), 23-43.

Gutiérrez, R. (2007). Las misiones circulares de los jesuitas en Chiloé. Apuntes para una historia singular de la evangelización. Apuntes, 20(1), 50-69.

Harvey, D. (1998). La condición de la postmodernidad. Investigación sobre los orígenes del cambio cultural. Buenos Aires: Amorrortu.

Hernández, J. y Moreno, R. (2010). La Misión y los jesuitas en América española, 15661797: cambios y permanencias. Madrid: CSIC.

Holland, C. (2009). Enciclopedia de grupos religiosos en América Latina y el Caribe: Religión en Chile. San Pedro, Costa Rica: PROLADE.

Lerma, E. (2013). Espacio vivido: del espacio local al reticular. Notas en torno a la representación social del espacio vivido en la globalización. Pueblos y Fronteras Digital, 8(15), 225-250.

Mansilla, M., Liberona, N. y Piñones, C. (2016). El influjo anglicano en el mundo mapuche (1895-1960). Charles Sadleir en los albores del liderazgo mapuche post-reduccional. Estudios Ibero-Americanos, 42(2), 582-605.

Menard, A. (2013). Libro diario del Presidente de la Federación Araucana Manuel Aburto Panguilef. Santiago: CoLibris.

Moreno, R. (2007). Misiones en Chile austral: los jesuitas en Chiloé 1608-1768. Madrid: CSIC_Escuela de Estudios Hispanoamericanos.

Moreno, R. (2011). El archipiélago de Chiloé y los jesuitas: el espacio geográfico para una misión en los siglos XVII y XVIII. Magallania, XXXIX(2), pp. 47-55.

Muñoz, J. (2018). Empresariados y política. Estudios sobre las relaciones políticas de los empresarios germanos de la provincia de Llanquihue (1891-1914). Santiago: Editorial RIL-ULagos.

Nicoletti, M. (2012). La Patagonia como territorio en disputa: tensiones entre el Estado, la Iglesia y la congregación salesiana por el espacio misionero. Cultura y Religión, 6(1), 183-203.

Olssen, E. (1899). The Dark Continent... at Our Doors: Slavery, Heathenism, and Cruelty in Southamerica. Nueva York: M.E. Munson Publisher.

Ospina, A. (2015). Purificando la tierra. Colonizando el espíritu: conflicto armado y religiosidad en la mítica Marquetalia. Anuario de Historia Regional y de Las Fronteras, 20(2), 101-124.

Oyarzún, A. (1921). Reminiscencias históricas de la obra evangélica en Chile. Temuco, Chile: Editorial Alianza.

Rodrigues, J. (2016). Territorialidades de la fe en el catolicismo brasileño: espacialidad y temporalidad en las nuevas comunicaciones. Cultura y Religión, 10(2), 65-79.

Scholtus, S. (2020). Mujeres y liderazgo en los inicios de la Iglesia Adventista del Séptimo Día en Argentina y Sudamérica (1894-1930). Cultura y Religión, 14(1), 58-79.

Serrano, S. (2008). ¿Qué hacer con Dios en la República? Política y secularización en Chile (1845-1885). Santiago: FCE. 
Shannon, J. (1997). La Alianza en Argentina 1897-1997. Buenos Aires: Inédito.

Simpson, A. (1979). El evangelio cuádruple. Harrisburg, Pa.: Christian Publications. Recuperado de https://vdocuments.mx/el-evangelio-cuadruple-simpson.html

Valdivia, I. (1947). Wenceslao Valdivia L. Primer bautista chileno. 1860-1935. Valparaíso, Chile.

Woerner, D. (ed.) (1997). Desde el siglo y hasta el siglo, Tú eres Dios. Temuco, Chile: Editorial Alianza.

Zabala, J. (2008). Los colonos y la escuela en la Araucanía: los inmigrantes europeos y el surgimiento de la educación privada laica y protestante en la región de La Araucanía (1887-1915). Universum, 23(1), 268-286.

\section{Cómo citar este artículo}

Escobar, D. Y Núñez, P. (2020). El establecimiento y expansión de la misión evangélica the Christian and Missionary Alliance en el sur de Chile (1897-1905). Revista Cultura \& Religión, 14(2), 56-78. 